\title{
POSITIONING ACCURACY ANALYSIS AND APPLICATION FOR WORLDVIEW-1 STEREO IMAGERY
}

\author{
XIAO Zhou ${ }^{a, b}$ Yang Bogang ${ }^{a, b}$ ZHANG Haitao ${ }^{a, b}$ \\ ${ }^{a}$ Beijing Institute of Surveying and Mapping, No.15 Yangfangdian Road,100038, Beijing China, \\ ${ }^{\mathrm{b}}$ Beijing Key Lab of Information Engineering in City Space, 100038, Beijing China \\ xiaozhou@bism.cn
}

KEY WORDS : WorldView-1; High resolution satellite; Stereo images; Positioning accuracy

\begin{abstract}
ABS TRACT:
This article introduced the progress of processing the WorldView-1 satellite image by using the air triangulation method. And different adjustment models were used to improve the vendor provided RPC (Rational Polynomial Coefficients) accuracy.WorldVfew-1 images in Beijing are used to test the correction accuracy of these adjustment models. Results show that the systematic errors of RPC model can be eliminated using a small amount of control points. The planar RMSE can reach 1.6 pixels( 0.9 meter).
\end{abstract}

\section{INTRODUCTION}

Digital Globe Company successfully launched a new generation of high resolution imaging satellite WorldView-1 in September 18, 2007. After launching, WorldView-1 became the highest resolution, and fastest responsive commercial satellite around world. This satellite is running at a height of 450 kilometres the sun synchronous orbit, and inclination 98 degrees, cycle $93.4 \mathrm{~min}$. The average revisit period is 1.7 days, satellite panchromatic image system with very large capacity to crab $0.5 \mathrm{~m}$ resolution image around 50000 $\mathrm{km} 2$ every day. The satellites also can rapid aim the targets and effectively get the same track stereoimaging. The satellite can not only obtain the resolution of $0.5 \mathrm{~m}$ images, but also make positioning accuracy up to $6.5 \mathrm{~m}$ without the ground control points ${ }^{[1]}$.

But some technical security problems, WorldView-1 provides a non-rigorous geometric sensor model to user - the RPC model, which is replaced the strict collinear geometric model ${ }^{[2]}$. Obviously, this strategy reduces the professional standards of users, but because it's a non-strict geometric model, the stereo positioning accuracy has been affected. So, how to improve the accuracy has been a focus of attention. This paper used WorldView-1 image data and a large number of high precision control point data of Beijing area to estimate the stereo positioning and regional adjustment accuracy of RPC stereo-pair model for
WorldView-1. And according to the analysis results, we explored the practical ability for different adjustment model under various conditions.

\section{INTRODUCTION OF WORLDVIEW-1 S TEREOTACTIC}

WorldView-1 does not provide orbit parameters, and not provide the original image and not provide rigorous geometric model strategy. It only provides the rational polynomial coefficient RPC (Rational Polynomial Coefficients), which is used by the rational function model. Generally, we use the RPC model to do the photogrammetric processing for WorldView-1 data. The essence of RPC model is the rational function model, through regularization pre-processing, object and image coordinates of RPC model are located in [-1, 1] which is in order to improve the stability of the model. RPC file is the important data files for WorldView-1 stereo pair model, unfortunately, core parameter information of sensor has been hidden. There are 90 RPC parameters in total (80 for rational function coefficient, 10 for the regularization parameters ).They constitute together a WorldView-1 satellite images of the rational function model ${ }^{[3]}$. Usually you can use the rational function model (RPC) as WorldView-1 image data imaging geometric model to process the photogrammetric, such as orthophoto correction, stereo mapping, DEM extraction.

In general, WorldView-1 remote sensing image can't meet the application positioning precision 
requirements of urban surveying and mapping without ground control. Usually we require the ground control points to correct the error of RPC system using a polynomial adjustment model, in order to improve the directional accuracy.

\section{WORLDVIEW-1 ORIENTED MATHEMATICAL MODEL}

Polynomial adjustment model depends on the deformation characteristics of image and RPC expression. In this experiment, we use to analyze the adjustment mathematical model for translation and the way for RPC $+2 \mathrm{D}$ affine transformation. We will do a simple introduction for the RPC model ${ }^{[4]}$, translation transformation, affine transformation ${ }^{[5]}$ and the corresponding adjustment mathematical model.

3.1

\section{RPC model}

$$
\begin{gathered}
X=\frac{\operatorname{Num}_{S}(B, L, H)}{\operatorname{Den}_{S}(B, L, H)} \\
Y=\frac{\operatorname{Num}_{L}(B, L, H)}{\operatorname{Den}_{L}(B, L, H)}
\end{gathered}
$$

In up formulas, $(B, L, H)$ are the regularization of terrestrial coordinates; $(X, Y)$ are the normalized image coordinates.

\subsection{Translation transforms}

The coordinate origin of the two Cartesian coordinates do the simple translation.

$$
\begin{aligned}
& x=s+a_{0} \\
& y=l+b_{0}
\end{aligned}
$$

In up formulas, $(x, y)$ as the control points in the image of the measured coordinates; $(s, l)$ as projection value of ground control point using RPC projection onto the image plane.

\subsection{Dimensional affine transformation}

Affine transformation takes into account the inconsistency in two direction scale between transverse axis and longitudinal axis. We divide coefficient of transverse and longitudinal axis into two directions of scaling coefficients, while increase the horizontal axis and the vertical axis vertical system error correction. The affine transformation completely is a polynomial transform, can be used to correct translation, scale and rotation, affine deformation linear deformation error. It is a commonly used in remote sensing image geometric correction method.

$$
\begin{aligned}
& x=a_{0}+a_{1} s+a_{2} l \\
& y=b_{0}+b_{1} s+b_{2} l
\end{aligned}
$$

$(x, y)$ as the measured coordinates in the control points of image; $(s, l)$ for ground control point using RPC projection onto the image plane. This transformation parameters and the parameters of RPC model are the satellite parameters of strict imaging geometric model.

\section{RESULTS AND ANALYS IS}

\subsection{Platform and test data}

In this study, we chose two scene WorldView-1 image data on July third in 2008 in Beijing area, the data for a stereo image pair. Data level is the basis of stereoscopic imaging products (stereo 1B ). Table 1 is the image data of some acquisition parameters.

Table 1 Data parameter of test image

\begin{tabular}{||l|l||}
\hline \hline Image Data & 08JUL03032443 \\
\hline Time & July,03,2008 \\
\hline Size of image & $35180 \times 21444$ \\
\hline GSD & $0.561 \mathrm{~m}$ \\
\hline Trackside Perspective & $33.8^{\circ}$ \\
\hline $\begin{array}{l}\text { Vertical Trackside } \\
\text { Perspective }\end{array}$ & $61.74^{\circ}$ \\
\hline
\end{tabular}

The major topographic features in this area are urban and mountains. We used 48 points as ground control points, as orientation and inspection points according to schemes. These points are evenly distributed on the plane and elevation, elevation ranges from about $30.33 \mathrm{~m}$ to $55.11 \mathrm{~m}$. Orientation and inspection points were obtained from aerial control points in 2008, accuracy in $\mathrm{cm}$ level. Precision of coordinates by Digital Photogrammetry Workstation can reach subpixel level.

\subsection{Test scheme}

This paper chooses the translational transformation and affine transformation model to improve accuracy of WorldView-1 images RPC imaging geometric model. And in accordance with the control points and check points in the plane and elevation, we distribute 
situation of groups, designed 6 different control points and check point combination for test precision plan (See table 2 ), the remain points as the check points. These test schemes were used to evaluate RPC accuracy for different polynomial adjustment models in different control conditions and improve the applicability, provide the evidence for the practical application.

Table 2 the scheme for control points and check point

\begin{tabular}{||c|l|l||}
\hline Scheme & $\begin{array}{l}\text { No. of } \\
\text { GCP }\end{array}$ & Position description \\
\hline 1 & None & Using RPC parameter \\
\hline 2 & 1 & In the center of image \\
\hline 3 & 5 & $\begin{array}{l}\text { One in the center of } \\
\text { image, other 4 points }\end{array}$ \\
\hline
\end{tabular}

\begin{tabular}{||l|l|l||}
\hline \hline & & around 4 corners \\
\hline 4 & 15 & $5 \times 3$ \\
\hline 5 & 16 & $4 \times 4$ \\
\hline 6 & 25 & $5 \times 5$ \\
\hline
\end{tabular}

\subsection{Result and analysis}

According to the design schemes of test, this paper did different combinations of test data for the control points and check points in the different distributions, and using translational transformation and affine transformation model to improve the WorldView1 image RPC imaging geometric model accuracy, table 35 respectively listed RMSE statistical data under these test schemes of check points. Units are meter.

Table 3 The result of RPC model directly position

\begin{tabular}{|c|c|c|c|c|c|c|c|c|c|c|c|c|c|}
\hline \multirow{3}{*}{ Scheme } & \multirow{3}{*}{$\begin{array}{l}\text { Position } \\
\text { description }\end{array}$} & \multicolumn{6}{|c|}{ Accuracy of control points } & \multicolumn{6}{|c|}{ Accuracy of check points } \\
\hline & & \multicolumn{3}{|c|}{ Actual accuracy } & \multicolumn{3}{|c|}{ Max. residual error } & \multicolumn{3}{|c|}{ Check accuracy } & \multicolumn{3}{|c|}{ Max. residual error } \\
\hline & & $\mathrm{X}$ & $\mathrm{Y}$ & $\mathrm{Z}$ & $\mathrm{X}$ & $\mathrm{Y}$ & $\mathrm{Z}$ & $\mathrm{X}$ & $\mathrm{Y}$ & $\mathrm{Z}$ & $\mathrm{X}$ & $\mathrm{Y}$ & $\mathrm{Z}$ \\
\hline $\begin{array}{c}\text { Scheme } \\
1\end{array}$ & $\mathrm{RPC}$ & & & & & & & 32.07 & 59.06 & 9.61 & -33.02 & -60.15 & 10.64 \\
\hline
\end{tabular}

Table 4 The result of translation transform model

\begin{tabular}{|c|c|c|c|c|c|c|c|c|c|c|c|c|c|}
\hline \multirow{3}{*}{ Scheme } & \multirow{3}{*}{$\begin{array}{l}\text { Position } \\
\text { description }\end{array}$} & \multicolumn{6}{|c|}{ Accuracy of control points } & \multicolumn{6}{|c|}{ Accuracy of check points } \\
\hline & & \multicolumn{3}{|c|}{ Actual accuracy } & \multicolumn{3}{|c|}{ Max. residual error } & \multicolumn{3}{|c|}{ Check accuracy } & \multicolumn{3}{|c|}{ Max. residual error } \\
\hline & & $\mathrm{X}$ & $\mathrm{Y}$ & $\mathrm{Z}$ & $\mathrm{X}$ & $\mathrm{Y}$ & $\mathrm{Z}$ & $\mathrm{X}$ & $\mathrm{Y}$ & $\mathrm{Z}$ & $\mathrm{X}$ & $\mathrm{Y}$ & $\mathrm{Z}$ \\
\hline $\begin{array}{c}\text { Scheme } \\
2 \\
\end{array}$ & 1 & & & & & & & 0.48 & 0.88 & 0.92 & 1.19 & 1.55 & 1.28 \\
\hline $\begin{array}{c}\text { Scheme } \\
3 \\
\end{array}$ & $4+1$ & 0.27 & 0.36 & 0.57 & 0.86 & 0.48 & -0.97 & 0.50 & 0.57 & 0.63 & 0.87 & 0.83 & 0.92 \\
\hline $\begin{array}{c}\text { Scheme } \\
4\end{array}$ & $5 \times 3$ & 0.32 & 0.46 & 0.52 & 0.77 & 0.63 & -0.81 & 0.35 & 0.53 & 0.61 & 0.80 & 0.79 & 1.00 \\
\hline $\begin{array}{c}\text { Scheme } \\
5 \\
\end{array}$ & $4 \times 4$ & 0.24 & 0.33 & 0.58 & 0.58 & 0.42 & 0.82 & 0.55 & 0.46 & 0.59 & 0.72 & 0.67 & 0.94 \\
\hline $\begin{array}{c}\text { Scheme } \\
6 \\
\end{array}$ & $5 \times 5$ & 0.35 & 0.51 & 0.42 & 0.73 & 0.79 & -0.91 & 0.38 & 0.45 & 0.50 & 0.68 & -0.78 & -1.02 \\
\hline
\end{tabular}

Table 5 the result of 2Dimensional affine transformation model

\begin{tabular}{|c|c|c|c|c|c|c|c|c|c|c|c|c|c|}
\hline \multirow{3}{*}{ Scheme } & \multirow{3}{*}{$\begin{array}{l}\text { Position } \\
\text { descripti } \\
\text { on }\end{array}$} & \multicolumn{6}{|c|}{ Accuracy of control points } & \multicolumn{6}{|c|}{ Accuracy of check points } \\
\hline & & \multicolumn{3}{|c|}{ Actual accuracy } & \multicolumn{3}{|c|}{ Max. residual error } & \multicolumn{3}{|c|}{ Check accuracy } & \multicolumn{3}{|c|}{ Max. residual error } \\
\hline & & $\mathrm{X}$ & $\mathrm{Y}$ & $\mathrm{Z}$ & $\mathrm{X}$ & $\mathrm{Y}$ & $\mathrm{Z}$ & $\mathrm{X}$ & $\mathrm{Y}$ & $\mathrm{Z}$ & $\mathrm{X}$ & $\mathrm{Y}$ & $\mathrm{Z}$ \\
\hline Scheme 3 & $4+1$ & 0.38 & $\begin{array}{l}0 . \\
25\end{array}$ & 0.44 & -0.79 & -0.65 & 0.81 & 0.46 & 0.50 & 0.42 & -0.82 & -0.89 & -0.94 \\
\hline Scheme 4 & $5 \times 3$ & 0.26 & $\begin{array}{l}0 . \\
29 \\
\end{array}$ & 0.30 & 0.71 & -0.69 & 0.77 & 0.48 & 0.52 & 0.51 & -1.00 & 0.81 & -1.22 \\
\hline Scheme 5 & $4 \times 4$ & 0.36 & $\begin{array}{l}0 . \\
38 \\
\end{array}$ & 0.35 & 0.68 & 0.72 & 0.85 & 0.40 & 0.45 & 0.47 & 0.84 & 0.82 & -0.97 \\
\hline Scheme 6 & $5 \times 5$ & 0.38 & $\begin{array}{l}0 . \\
41\end{array}$ & 0.38 & -0.83 & -0.76 & 0.86 & 0.29 & 0.43 & 0.48 & 0.68 & -0.78 & -1.02 \\
\hline
\end{tabular}

Affine transformation requires more than 3 control points, so it only gives the Scheme 3-6. 
According to results of table 3-5, we can draw the following conclusions:

1. Without control points, ground positioning accuracy of WorldView-1 is about $60 \mathrm{~m}$, the height precision is about $10 \mathrm{~m}$.

2. Adding a few control points ( 1 or 5 ), the system error of RPC model was been effectively eliminated. The plane orientation point accuracy of WorldView-1 is $0.7 \sim 0.9 \mathrm{~m}$ ( 2 pixels ). The height precision at around is $0.8 \mathrm{~m}$ ( 2 pixels ).

3. Two adjustment schemes almost have the same accuracy and results remain stable. This verify that RPC model error is the main source of systematic error. Using a simple object translation Scheme has basically satisfied the usual location requirements.

\section{CONCLUSIONS}

RPC model of WorldView-1 image replaces the strict geometric model based on collinear equation. Since satellite observations have certain errors, so the accuracy of original RPC parameter positioning is limited. It needs to do correct to satisfy the requirements of application in mapping. This paper used two kinds of indirect optimization algorithm: translation transformation and affine transformation model as the RPC model, and applied to the WorldView-1 stereopair adjustment calculation, research the different accuracy of positioning. The test results show that, the RPC model has better stability, with only a few ground control points which can effectively eliminate the systematic errors in the RPC model. The plane of orientation error of WorldView-1 image can reach $+0.70 \mathrm{M}$, elevation is better than $1 \mathrm{~m}$. From the experimental results, the translational transformation model is a simple and good adaptability, high precision for processing WorldView-1 image data adjustment model. In practical field work operation, especially the less control point, poor distribution, or difficult terrain conditions, such as the border, islands, mountains, coast, mountains, alpine, lakes, forests, deserts and other regions, we recommend to use translation model for WorldView-1 image data processing.

\section{References}

Digital Globe.WorldView-1 Imagery Products Quick Reference Guide(Version1.2)[EB/OL].2008.http://www.digitalglobe.com/digitalglobe2/file.php/545/WV1_Product_QR_Guide. pdf.

Zhang Yongsheng,Gong Danchao,Liu Jun 2007. Application of the High-resolution Satellite Images [M] Science Press Beijing

Fraser C.S\& Ravanbakhsh M,2009, Geo-reference Performance of GEOEYE-1:Early Indications of Metric Performance [C]. ISPRS High-Resolution Earth Imaging for Geospatial
Information Workshop, Hannover Germany, 2009 June 25,page 1-6

Chai Dengfeng\& Zhang Dengrong,2007, Geometric Rectification Methods of High-resolution Satellite Images [M]. Zhejing University Press. Zhejing

Zhang Guo,Zhang Jixian,Chen Xiangdong, 2009, An Hong Block-Adjustment with SPOT-5 Imagery and Sparse GCPs Based on RFM [J].ACTA GEODAETICA ET CARTOGRAPHICA SINICA. 2009 38(4):302-310 